Running head: GOVERNANCE IN SPORT: A SCOPING REVIEW

Governance in Sport: A Scoping Review

Mathew Dowling ${ }^{1}$ \& Becca Leopkey ${ }^{2}$ \& Lee Smith ${ }^{1}$

${ }^{1}$ Anglia Ruskin University, England

${ }^{2}$ University of Georgia, United States

Submitted: 13/03/18 
GOVERNANCE IN SPORT: A SCOPING REVIEW

\begin{abstract}
This article examines the current state of sport governance research within the field of sport management. In adopting Arksey and O’Malley’s (2005) framework, a scoping review was conducted involving a comprehensive search of all published literature between 1980 and 2016. The process involved searching four electronic databases and a manual search of sport management journals. The search identified $(n=243)$ journal articles that examined sport governance related issues. Findings are presented as a frequency and thematic analysis. The frequency analysis reveals a notable increase in sport governance research in recent years with a large number of non-empirical studies focused on the not-for-profit sector. The thematic analysis draws upon and extends Henry and Lee’s (2004) three notions of governance and identifies sport governance-related topics, research contexts and social issues. Findings indicate that all three forms of governance (organizational, systemic, and political) have contributed to our understanding of sport governance but more empirical and theoretically driven research is needed.
\end{abstract}

Keywords: sport governance, research methods, sport organisation governance 


\section{GOVERNANCE IN SPORT: A SCOPING REVIEW}

\section{Governance in Sport: A Scoping Review}

Governance in sport has become a central concern to sport management academics and practitioners in recent years as evidenced by the number of keynotes (e.g., Shilbury, 2015), special issues (e.g., Dolles \& Söderman, 2011), and books (e.g., Hoye \& Cuskelly, 2007; King, 2017) dedicated to examining sport governance issues. This interest has emerged, in part, from broader societal concerns surrounding governance (e.g., Enron scandal and the global economic crisis) but also due to recent high profile failures specifically within the context of sport (e.g., Fédération Internationale de Football Association (FIFA) and the Russian doping scandal). In general, the application of governance to the sport context sensitizes us to how sport

organizations and systems are steered and controlled. Central to the concept of governance is the notion of power, where power lies within sport organizations and systems, and the extent to which power has shifted.

Yet despite governance being recognized as a "paradigm-generating concept" (Bellamy \& Palumbo, 2010, p. xii) that "has spawned a veritable cottage industry of its own” (Grix \& Phillpots, 2011, p. 6), there has been no systematic attempt to capture the extent of this burgeoning literature base by either public administration, management or sport management scholars. It is also evident that despite much academic and practitioner interest in the concept of governance, definitional agreement within the broader public administration and management literature remains problematic. The concept of governance has been described as confusing (Kjaer, 2004), elusive (Pierre, 2000), and fuzzy (Colebatch, 2014), with its application to date being imprecise (Bevir, 2012) and with “too many meanings to be useful” (Rhodes, 1996, p. 660).

Furthermore, the ongoing definitional ambiguities and debates within the broader public 


\section{GOVERNANCE IN SPORT: A SCOPING REVIEW}

administration and management literature, we argue, have also been reflected in the way in which the concept of governance has been employed within the sport management literature with academics discussing a plethora of sport management related issues ranging from specific micro-

level concerns such as governing board performance and athlete sanctions to broader macro-level discussions of the changing dynamics between government and governmental agencies (civil state) and sport (society). The breadth of coverage of governance-related topics is also apparent from the variety of definitions employed by sport scholars (see Table 1 for a select overview of definitions). What can also be drawn from Table 1 is that different sport scholars have adopted different definitions of governance, if indeed they adopt a definition at all, based upon their specific interests and research traditions. Understanding these differences is therefore important not only to avoid duplication of efforts, but also because, in our view, they have much to offer one another in terms of knowledge and understanding of governance within sport and how changing governance arrangements are influencing sport organizations and practitioners.

\section{***Insert Table 1 (sport governance definitions) about here***}

In acknowledging this definitional ambiguity and the continuing growth and breadth of sport governance discussions that have emerged, it is appropriate and necessary at this conjuncture to begin to organize and synthesize these distinct, yet complimentary literature bases in order to understand how researchers have employed the notion of sport governance. This will enable scholars to take stock of what is currently known about governance within the context of sport and to identify potential areas for further research. The purpose of this study therefore is to examine the current state of sport governance research within and beyond the field of sport management through a scoping review of the literature. Specifically, this scoping review aims to: (i) identify how sport governance has been utilized within the literature; (ii) map out the sport 


\section{GOVERNANCE IN SPORT: A SCOPING REVIEW}

governance literature and (iii) identify potential future directions of research.

In doing so, we make the following contributions to the sport management literature.

First, the review facilitates further progression and understanding of the sport governance domain through organizing and synthesizing this currently disparate research area. To progress in science we must be aware of, and understand, the literature that exists in an area of study. The adoption of a scoping review, as opposed to a systematic or meta-analysis for example, is particularly appropriate at this conjuncture given the current definitional ambiguities that exist within sport governance research. A scoping review therefore enables academics interested in sport governance to conceptualize the contributions from several disciplines and identify gaps in current knowledge that still remain unanswered. In conducting this review, we also offer a second contribution, in that we provide the first attempt to conceptualize (or map) the sport governance literature in its entirety. Third and finally, in utilizing Henry and Lee’s (2004) definition as our starting point, we provide a more specific contribution to the sport governance literature by extending their conception of sport governance by further explicating sub-themes and types of studies that have been conducted within each of their general approaches to sport governance. The broader outcome of synthesizing and mapping the literature and extending Henry and Lee’s notions of governance, we believe, is a more holistic and nuanced understanding of governance within sport.

\section{Methods}

Scoping reviews are a way of synthesizing knowledge in a given area, especially when that area is emergent and complex. They are increasingly popular in other domains such as medicine and health (e.g., Pham et al. 2014), but so far remain uncommon within the sport management literature (for exception see Inoue, Berg, \& Chelladurai, 2015). The purpose of a scoping review 


\section{GOVERNANCE IN SPORT: A SCOPING REVIEW}

is to examine the extent and range of research in an area, determine the value of further reviews, summarize and disseminate research findings, and identify research gaps in the existing literature (Arskey \& O’Malley, 2005). According to Colquhoun et al. (2014),

A scoping review or scoping study is a form of knowledge synthesis that addresses an exploratory research question aimed at mapping key concepts, types of evidence, and gaps in research related to a defined area or field by systematically searching, selecting, and synthesizing existing knowledge (pp. 1292-1293).

In contrast to a systematic review, scoping reviews do not claim to be exhaustive, nor do they make an assessment of research quality. Rather, scoping reviews attempt to provide extensive (rather than intensive) coverage of a select topic area. In this manner, scoping reviews seek to 'map the landscape' of a research area in order to summarize research and convey the breadth of a field (Levac, Colquhoun, \& O’Brien, 2010). Although there is no agreed upon protocol for conducting scoping reviews, this study adopted Arskey and O’Malley’s (2005) scoping review methodological approach as it is the most commonly used framework. In employing Arskey and O’Malley’s protocol, the review proceeded through the following stages: (i) identification of research question; (ii) determination of relevant studies; (iii) study selection; (iv) charting the data (data extraction); and (v) collating, summarizing and reporting the results.

\section{Identification of Research Question}

According to Arskey and O’Malley (2005), a research question should be derived in order to guide the search strategy. Research questions should not be too narrow as to limit the analytical process and should be broad enough to generate breadth of coverage and identify all relevant literature. Consequently, consistent with our aims, the following research questions were derived in order to inform the study: (i) how has sport governance been utilized within the literature? (ii) 
GOVERNANCE IN SPORT: A SCOPING REVIEW

what topic areas of sport governance have been studied? (iii) what are the emergent areas and future directions of research within the sport governance domain?

\section{Determination of Relevant Studies}

To ensure comprehensive coverage of the sport governance literature, studies were identified via three sources: electronic databases (SPORTDiscus, Scopus, Web of Science and Science Direct), manual search of sport management journals, and reference list inspections. The four electronic databases were selected to ensure the widest coverage of the sport governance literature. Both the electronic database search and manual searches of sport management journals took place in October 2016. The electronic database search terms "Sport” AND “Governance” [All-Fields] yielded a total 6625 hits [SportDiscus (65), Scopus (5305), Web of Science (305), and Science Direct (950)]. The search was refined by only including (i) peer-reviewed journal articles (in press and review articles were also included) that (ii) investigated sport governance related issues as defined by Henry and Lee (2004); (iii) were published between 1980 and $2016^{1}$ (iii) and were written in the English language. This process of refinement produced 243 articles for further analysis. A graduate student then manually searched all journal article reference lists and the three major sport management journals (Journal of Sport Management, Sport Management Review, and European Sport Management Quarterly) as well as other relevant journals that service the sport management community (e.g., International Journal of Sport Policy and Politics, International Journal of Sport Marketing and Management).

\section{Study Selection}

In order to eliminate studies that did not directly answer our research questions, the authors then

\footnotetext{
1 The period 1980-2016 was selected as an appropriate timescale for analysis as Rhodes (1996) describes 1980 as the 'governance turn' whereby the shift from government to governance originally occurred. The first sport management journals were also established during this time (e.g., Journal of Sport Management - 1984). This timeframe therefore ensured full coverage of the sport governance literature.
} 


\section{GOVERNANCE IN SPORT: A SCOPING REVIEW}

independently conducted a title and abstract review of all citations to ensure that they met the above inclusion criteria. Articles were excluded if the three reviewers identified them as not meeting the criteria. In the instances whereby an article was identified for exclusion by one researcher and not another, then a full copy of the article was obtained, reviewed by all researchers, and a collective decision was made through discussion. Through this process a total of 243 studies were selected for further analysis.

\section{Charting the Data}

The next stage of the process involved charting and data extraction from the 243 citations identified from the search process. According to Arksey and O’Malley (2005), the charting is a technique for organizing and interpreting data into qualitative themes. We carried out the data extraction and chart process using Excel and collected the following information on all citations: author, publication year, abstract, governance type - as defined by Henry and Lee (2004) (organizational, systemic, political), type of study (e.g., empirical), methodology (qualitative, quantitative or mixed methods), data collection strategy (e.g., questionnaires, interviews), (h) study population (e.g., national sport organizations, club), (i) sector (not-for-profit, public or professional), type of sport examined (e.g., football, basketball), country of data collection, study aim/purpose, key findings, and key words. The selection of these variables was based upon the initial research questions (Levac et al., 2010). The first and second author then undertook a pilot charting process that involved data extraction (charting) from 55 randomly selected citations to become familiarized with the process and ensure consistency across the research team. This was followed by the allocation of all the remaining articles to the first and second author, who both carried out the remaining data extraction for all citations. Where authors were undecided about classification, all three authors re-reviewed and discussed the article until a consensus was 
GOVERNANCE IN SPORT: A SCOPING REVIEW

reached.

\section{***insert Figure 1 (search process) about here***}

\section{Collating, Summarizing and Reporting Results}

Consistent with Arksey and O’Malley and previous scoping reviews within the sport management domain (Inoue et al., 2015), a frequency and thematic analysis was conducted. Frequency analysis is a descriptive statistical method that shows the number of occurrences for each variable. For purposes of this scoping review, the variables extracted for the frequency analysis included: publication year, data origin (country), journal, methodology, study population and sport. The thematic analysis involved the first and second authors identifying patterns across data set in relation to the proposed research questions. In this case, we sought commonly reoccurring themes associated with what is currently known about sport governance within the existing literature through an inductive and iterative open-coding process.

\section{Findings}

\section{Frequency Analysis Findings}

Study descriptive characteristics are displayed as frequencies in Table 2. The majority of studies (68\%) were carried out in not-for-profit $(n=82)$ or spanned multiple sectors $(n=82)$. The most common study population within sport governance studies were National Sport Organizations $(n=26)$ and leagues $(n=22)$ and were carried out in multiple countries ( $n=43)$; most notably England (n=30), Canada ( $\mathrm{n}=27)$ and Australia $(\mathrm{n}=27)$ and focused on multiple sports $(\mathrm{n}=71)$ or football ( $n=68)$. Out of the 243 identified manuscripts, 18 were published between 1982 and 2003 whereas 225 were published between 2004 and 2016 (see Figure 2) Approximately 27\% of all sport governance articles were published in three leading Sports Management journals, including: Sport Management Review (n=28), Journal of Sport Management $(n=20)$, and 
GOVERNANCE IN SPORT: A SCOPING REVIEW

European Sport Management Quarterly $(n=18)$. There are five additional journals of note that contain approximately 26\% of all articles: International Journal of Sports Policy (n=18), International Review for the Sociology of Sport $(n=12)$, Managing Sport and Leisure $(n=12)$, Soccer \& Society $(n=11)$, and the International Sports Law Journal $(n=10)$ (see supplementary Figure 1)

\section{***insert Figure 2 (publication frequency) about here*** \\ ***insert Table 2 (descriptive characteristics) about here ${ }^{* * *}$}

\section{Thematic Analysis Findings}

A thematic analysis was adopted to identify and report themes (Braun \& Clarke, 2006). This process involved two researchers reviewing the data set independently to generate an initial list of codes. Code generation occurred through an inductive and iterative process in which we deliberately chose not to adopt pre-existing themes within the sport governance literature as these would have limited the scope of our findings. These lists were then amended and refined through discussion between the researchers until a single list was agreed. During the latter stages of the analytical process, it became apparent to the researchers that emergent themes begun to coalesce around types of governance, research contexts, and related topic areas. These themes are discussed in more detail below and are summarized in Figure 3.

***insert Figure 3 (map of the sport governance literature) about here***

\section{Types of Governance}

As stated previously, the present study adopted Henry and Lee’s (2004) three general approaches or types of governance: organizational (or corporate), systemic and political. These types of governance were used during the present study as the basis for the inclusion criteria, during the citation selection process, and to organize and categorize the data. 
GOVERNANCE IN SPORT: A SCOPING REVIEW

Organizational governance. Organizational (or corporate) governance is "concerned with normative, ethically-informed standards of managerial behaviour” (Henry \& Lee, 2004, p. 24). This type of governance approach relates to the accepted norms, values and processes surrounding business conduct and management over sport organizations and governance practices that involve direct steering of sport organizations (Henry \& Lee, 2004). The scoping review identified several conceptual/theoretical papers that provided extensive (albeit narrative) reviews of this type of governance (e.g., Ferkins \& Shilbury, 2015; O’Boyle, 2012). These theoretical/conceptual papers were used during the charting stage to facilitate the development of sub-themes. Consistent with the nature of a scoping review, however, the pre-existing themes/categorizations from the literature (e.g., strategic capability, board conflict) were only used as an initial point of departure to ensure that themes were not restricted to the creation of sub-themes already identified in the literature.

The process identified 74 (30.3\%) citations that were classified as organizational governance and separated into two broad areas: governing board dynamics and management behavior and practice (see Supplementary Table 1 for an overview of organizational governance studies). Governing board dynamics studies focused on the issues surrounding the governance boards that oversee sport organizations, specifically they examined intra-board dynamics and the relationship between the governing boards and executive management. These could be further divided into the following sub-themes: board conflict, decision-making, performance, boardexecutive relationships, strategic capability and structure (roles and responsibilities); the most common of which were board structure (role and responsibilities) studies $(n=16)$. Ferkins and Shilbury (2012), for example, explored board member perceptions of strategic capability and the factors that enable and constrain board strategic function. Hoye and Cuskelly (2003) investigated 


\section{GOVERNANCE IN SPORT: A SCOPING REVIEW}

the relationship between board performance and the board-executive relationships. Readers are directed to Ferkins and Shilbury (2015) for a more comprehensive overview of this area.

A second set of organizational governance studies focused more on the socially acceptable norms and values surrounding sport organizations that often extended beyond the boardroom. These were studies more interested in the normative ethical principles and practices in which sport organizations should operate (Henry \& Lee, 2004) and were categorized into the following sub-themes: leadership and management, good governance; which could be further divided into its respective principles), and rules and regulations. Leadership and management studies focused on the norms and values of leading and managing sport organizations (e.g., Adriaanse \& Claringbould, 2014; Dortants \& Knoppers, 2016). There were also several studies that examined the principles of good governance ${ }^{2}$ as they relate to sport organizations. Chappelet (2011), for example, analyzed the accountability of the International Olympic Committee.

Several studies within this set $(n=7)$ focused on social responsibility and ethical related issues (e.g., Boudreaux et al. 2016; Zeidan \& Fauser, 2015) - see discussion on related areas and corporate social responsibility below. Sherry and Shilbury (2011) investigated the impact of social expectations on the management and governance of sport organizations.

Systematic Governance. Systematic governance is “concerned with the competition, cooperation and mutual adjustment between organizations in business and/or policy systems” (Henry \& Lee, 2004, p. 24). This type of governance focuses on the key shifts in the way that sport is organized and controlled. This often involves the need for mutual adjustment between sport organizations and stakeholders. Systemic governance therefore focuses on the relationships between

\footnotetext{
2 The seven principles of good governance outlined by Henry and Lee (2004) are transparency, accountability, democracy, responsibility, equity, effectiveness and efficiency. See Henry and Lee (2004) for a full elaboration of the principles.
} 


\section{GOVERNANCE IN SPORT: A SCOPING REVIEW}

organizations rather than directly over them (Henry \& Lee, 2004). Our scoping review identified 121/243 (49.8\%) systemic governance studies (see Supplementary Table 2 for an overview of systemic governance studies). The largest body of systemic related governance research ( $\mathrm{n}=27)$ centered on the changing governance structures within sport. Most of these studies investigated the changing nature of governance structures and the implications of this change for sport organizations (e.g., Goodwin \& Grix, 2011; Sotiriadou, 2009), while others examined the implications of field-level changes for the development of specific sports, for example, rugby (O’Brien \& Slack, 2003), horse racing (Hoye, 2006), baseball (Cousens \& Slack, 2005) and basketball (Washington \& Ventresca, 2008). There were also related studies $(n=15)$ that adopted a governance perspective to examine high performance sport systems or events. This group of studies was less interested in changing governance structures per se, but rather adopt a governance lens to examine sport systems or events. Girginov (2012), for example, adopted a governance perspective to explore how the legacy of the London 2012 Olympic Games were governed. Similarly, Phillips and Newland (2014) explored the emergent models of delivering triathlon events in the US and Australia.

Other studies $(\mathrm{n}=27)$ focused on the role of individual or multiple actors in sport governance arrangements. These studies either examined the influence of individual or multiple actors on governance arrangements or how changes in governance arrangements have impacted the way sport organizations operate. As an example of the former, Wagner (2011) analyzed the creation of the World Anti-Doping Agency (WADA) and role of international federations, FIFA and the International Association of Athletics Federations (IAAF), in shaping these new governance arrangements. In contrast, Nite (2016) examined the institutional work of the National Collegiate Athletics Association (NCAA) within the organizational field of US 


\section{GOVERNANCE IN SPORT: A SCOPING REVIEW}

collegiate athletics. The study highlights how sport organizations (actors) can formulate defensive narratives to shape organizational fields.

Another body of research $(n=24)$ centered on inter-organizational relationships and dynamics between sport organizations within governance structures. Van den Hurk and Verhoest (2016), for example, explored the use of standard contracts in public-private partnerships in the Belgium sport sector. There were also inter-organizational and cross-sectoral partnership studies (e.g., Babiak, 2007; Babiak \& Thibault, 2009) that were deemed systemic governance studies based on Henry and Lee’s (2004) broad definition, despite not being prototypical sport governance studies (see related topics for further discussion on below). A closely connected emergent area of enquiry within the inter-organizational domain has been a handful of studies $(n=5)$ that have begun to examine the notion of collaborative governance, namely the involvement of the government, volunteer and private sector to optimize outcomes. Shilbury, O’Boyle, and Ferkins (2016) explored the utility of collaborative governance for sport governance research.

A fourth group of systemic governance studies $(n=12)$ addressed issues surrounding governance failures or poor governance; most notably failures in governance in football (e.g., Dorsey, 2015) but also doping (e.g., Kornbeck, 2016; Miller, 2011). The connection between these studies and the organizational governance is also apparent as they involve issues surrounding normative business ethics, however, they were deemed systemic in that they focused on system-wide failings in governance.

Political Governance. Political governance is “concerned with how governments or governing bodies in sport 'steer', rather than directly control, the behaviour of organisations” (Henry \& Lee, 2004, p. 24). The notion of political governance therefore refers to the growing consensus 


\section{GOVERNANCE IN SPORT: A SCOPING REVIEW}

amongst (typically public administration) scholars that the contours between the state and society have fundamentality shifted - although quite to what extent power and control has shifted remains heavily debated (cf. Marsh, 2008; Rhodes \& Bevir, 2008). It is through these broader shifts in governing that governments have increasingly attempted to steer rather than row (Osborne \& Gaebler, 1992). According to Henry and Lee (2004), political governance involves achieving wider social and political objectives through strategic action involving direct and indirect mechanisms of intervention and control. Our scoping review identified 49/243 (22\%) citations that could be categorized as political governance at varying levels of analysis (see Supplementary Table 3 for an overview of political governance studies).

At the supra-national level, a body of research $(n=13)$ has examined the relationship between sport and the European Union (EU). The majority of these studies (11/13) focused on the influence of the EU on the way in which sport is organized and governed. Geeraert and Drieskens (2015), for example, investigated the limits of the EU's control on the autonomy of FIFA and the Union of European Football Association (UEFA). Others focused on how sport organizations have engaged with and interpreted EU policy and the influence of broader sociopolitical trends on sport. In regards to the former, Craven (2014) reviewed the 2013 football investigations as a means of understanding EU policy on sport and Garcia and Weatherill (2012) investigated how sport governing bodies engaged with the EU in order to minimize its impact. In

relation to the latter, Brand, Niemann, and Spitaler (2013) explored the Europeanization of sport through two case studies of Austrian and German football.

At the national level, a body of research $(n=16)$ has looked at the role and influence of national and local governments on sport. Grix (2009), for example, examined the impact of UK sport policy on the governance of athletics. Lusted and O'Gorman (2010) investigated the impact 
GOVERNANCE IN SPORT: A SCOPING REVIEW

of government policy interventions on grassroots football workforce illustrated through the English Football Association's (FA) Charter Standard Scheme and The Equity Strategy.

A final set of studies $(n=11)$ examined the role and influence of sport governing bodies in steering sport organizations and systems. These studies have primarily focused on the influence of regional (e.g., Gardiner \& Welch, 2011) and international federations (e.g., Meier \& Garcia, 2015) on sport organizations. Meier and Garcia (2015), for example, explored the power of FIFA over governments arguing that FIFA has influenced government decision-making through control of market access to global football.

\section{***insert Table 3 (type of governance) about here***}

\section{Governance Themes/Topic Areas}

\section{Related topics}

The review process identified several related topics that included governance and governance-related studies and were closely linked to governance yet were established areas of

study in their own right. Related topic areas included sport policy, corporate social responsibility, organizational change, law, and partnerships. These domains and their empirical and conceptual connection to governance will now be explored.

Sport Policy. A number of journal articles $(n=16)$ identified from the scoping review focused predominantly on policy, related governance shifts and their impact on sport (for exceptions see Garcia \& Weatherill (2012) and Green \& Houlihan (2006)). All of these studies were classified as either systemic or political governance and focused on high performance sport related issues with very few studies examining the impact or influence of sport policy on grassroots sport (see Lusted and O'Gorman (2010) for an exception). Goodwin and Grix (2010) for example, built upon decentered accounts of governance to argue that government has increased rather than lost 


\section{GOVERNANCE IN SPORT: A SCOPING REVIEW}

power and control over sport and educational sectors as a result of governance shifts. Similarly, Sam (2012) examines the influence of New Public Management principles and performance target setting specifically on National Sport Organizations in New Zealand. The remaining studies focused on the impact of policy or the influence of government on the ability of sport organizations to govern (e.g., Grix, 2009). One article of particular note, (Houlihan \& Green, 2009) examined the influence of broader governmental changes on governmental agencies.

Corporate Social Responsibility. A second related topic area identified from the review was the connection between Corporate Social Responsibility (CSR) and sport governance. The sport CSR literature also seemed to be closely connected with organizational sport governance (i.e. good governance and business ethics) but also have implications for systemic governance and the changing nature of inter-organizational relationships. Sponsors and media are increasingly playing an important role in the governance process - hence the crossover between CSR and sport governance. The CSR process is therefore a means through which to demonstrate good governance practices but also maintain inter-organizational relationships within governance networks. A handful of articles $(n=8)$ were identified from our scoping review that spanned the CSR-governance boundary, although there were no clear trends regarding their overall focus or interest. Zeidan and Frauser (2015), for example, examined the FIFA’s governance policies including corporate governance and CSR practices through the perspective of football fans. It was apparent, then, from our review that that CSR and sport governance an emerging but underdeveloped area of inquiry.

Organizational Change. A third related topic area was organizational change studies that were closely linked to sport governance. Much of the organizational change literature pre-dates the sport governance literature and we would suggest that earlier discussions surrounding sport 


\section{GOVERNANCE IN SPORT: A SCOPING REVIEW}

governance originated from within the organizational change literature (Kikulis, 2000). Our review also revealed a continued overlap between these areas, most likely because organizational theory and sport governance literature are both meso/macro perspectives seeking to explain organizational and systemic change. Cousens and Slack (2005), for example, explored field level change within professional baseball.

Law. A fourth related topic area identified from the review process was Law ( $\mathrm{n}=7)$. Legal issues have profound implications for governance arrangements, especially the rules and regulations that dictate them. Legalities often shape the nature of governance arrangements and the types of governance models adopted (e.g., China vs. European sport governance models), and power dynamics of actors within governance networks are often enforced through legal means (e.g., EU law, government funding etc.). Studies within this area include: examining European and national law through case studies of professional sport (Serby, 2016) and anti-doping (Kornbeck, 2016) regulations, understanding the legal frameworks, in which sport entities operate (van Kleef, 2014), and the usage of legal powers to govern sport (MacDonald \& Ramsey, 2016). Partnerships. The connection between sport governance and the partnership literature was also identified from the scoping review. The partnership literature closely linked to systemic governance (as discussed previously). This is because changes in governance structures from traditional hierarchical to modern approaches result in different partnership arrangements. Furthermore, modern governance structures are likely to have implications for partnership dynamics (resource-dependencies, reporting processes, and where power lies within these arrangements etc.). Thus, any shift towards a modern (network) governance structures are likely to increase the complexities of partnership arrangements within sport.

Sport for Development. Links between sport for development and the sport governance literature 
GOVERNANCE IN SPORT: A SCOPING REVIEW

also emerged in the scoping review. Although not as salient as some of the other related topics identified above, a small grouping of articles $(n=4)$ did reveal a connection. The majority of studies focused on how governing arrangements had been formed through sports for development initiatives and the role of different stakeholders (e.g., governing bodies, third party organizations) in policy implementation and program development (e.g., Philips \& Newland, 2014; Weinberg, 2012). Some studies in this area included Weinburg's (2012) investigation of the Asian Football Confederation’s programs AID27 and Vision Asia and their role in developing and increasing the standards of Asian football. Philips and Newland's (2014) research on triathlon development and delivery models found that third party organizations were taking on the traditional roles or sport governing bodies in the sport’s development. Thus, demonstrating a shift from traditional governing structures towards an increasingly networked based approach.

\section{Research contexts}

The thematic analysis also revealed several research contexts in which sport governance studies had been conducted. The themes below are by no means exhaustive or entirely mutually exclusive, many more were identified from the process and it became apparent that a number of citations spanned multiple research contexts (e.g., football event studies). Nonetheless, the three areas outlined below emerged from the review process as the most prevalent empirical sites for sport governance research.

Football. Football was identified as the most common theme within the dataset (50/243 citations, 21\%). Most studies primarily focused on the changing nature of professional football governance within Europe. A group of studies have examined the power and influence of key actors such as EU, FIFA, UEFA and FA within the football governance network. Geeraert and Drieskens 


\section{GOVERNANCE IN SPORT: A SCOPING REVIEW}

(2015) demonstrates the control of the EU over governing bodies within football through a principal-agent perspective and Dimitropoulos, Leventis, and Dedoulis (2016) examined the influence of UEFA's regulatory (i.e. accounting data) and monitoring processes on club accounting quality. Another set of studies also focused on the recent, high profile failures in world football governance (e.g., Dorsey, 2015; Peilke, 2013). For Dorsey (2015), issues within football are beyond financial corruption and the result of patronage, ungoverned relationships between sport and government, and the influence of middle-eastern autocrats, and skewed debates about mega-event bids. A final set of football studies looked at the change in rules and regulations in professional football such as Bosman ruling and player quota regulations (e.g., Gardiner \& Welch, 2011; Senaux, 2011) and changes in club ownership (e.g., Franck, 2010). One study of note (Welford, Garcia, \& Smith, 2015) examined fans perceptions of governance changes in football. Through the use of photographs and scrapbooks, fans identified dissatisfaction with several aspects of current football governance including financial, physical and social health of the sport. It was also noted that football citations were evenly spread across the three forms of governance.

Sports Events. The second largest research context that emerged from the data set was sport events $(n=27)$. The majority of which focused on large-scale and mega-events and many of these had a focus on the Olympic Movement. Within this group of studies, three main levels of governance were identified: the movement, particular editions of the Games and specific event management issues. For example, Chappelet (2016) looked at the shift from traditional event administration to a more complex networked governance approach to planning and implementing the Olympic Games. Girginov’s (2012) study examined the governance of event legacy at the London 2012. Governance sub-themes such as specific event management issues 


\section{GOVERNANCE IN SPORT: A SCOPING REVIEW}

(e.g., security, legacy) also emerged. For example, the notion of event legacy was commonly investigated from a governance perspective. Leopkey and Parent (2012) explored the institutionalization of the concept of governance within the Olympic field and its resulting need for governance mechanism to guide collective decision-making. Most citations with the sport event theme adopted systemic governance related focus as they were primarily interested the role stakeholders within the governance of sporting events. More specifically there were several studies that focused on the stakeholders of the event generally (e.g., Leopkey \& Parent, 2015; Parent, 2016) while others delved deeper into the roles of specific stakeholders within the governance of the event (e.g., Nichols, Grix, Ferguson, Griffiths, 2016; Parent, Rouillard, \& Leopkey, 2011).

Collegiate Sport. The scoping review identified collegiate sport as a research site for sport governance associated papers $(n=9)$. Many of the citations within this theme primarily focused on the role of the NCAA within the US collegiate education system (for exception see Erturan, Brison, and Allen, 2012, who comparatively examined the Turkish university sport system). More specifically, most articles highlight the dynamic nature of the collegiate governance network and document NCAA's attempts to obtain and maintain power within the network. Washington and Ventresca (2008), for example, documented the evolutionary struggles within US amateur basketball resulting in the current dominance of the NCAA within the US collegiate sport field. Articles also often addressed inequalities in rules and regulations of NCAA (gender, competition, revenue imbalances etc.). For example, Yiamouyiannis and Osborne (2012) examined female representation in leadership roles within the NCAA governance structure. Interestingly, 8/9 citations within this theme were categorized as systemic governance suggesting that most articles are focusing on the interactions of stakeholders within their associated 
GOVERNANCE IN SPORT: A SCOPING REVIEW

networks. There also seemed to be clear links to other themes identified within the review, for example, social themes such as gender inequalities and laws and rules and regulations that oversee collegiate sport.

\section{Social issues}

In addition to topic areas and research contexts the review process also identified a number of themes relating to societal issues surrounding governance. If sport is a reflection of society then sport governance has been used by academics as a theoretical/conceptual tool in which to reflect upon these broader societal concerns. Once again we acknowledge these themes not exhaustive or mutually exclusive, however, two salient social themes emerged from the thematic analysis: gender and corruption.

Gender. The first of the social themes that emerged from the data set were gender-related issues within sport $(n=19)$. All but one citation was classified as organizational governance. Some subthemes that emerged include female experiences of governing over sport (e.g., Radzi \& Abdullah, 2010), the gendering (e.g., Sibson, 2010) or creation, separation, and mergers of gender-specific sport organizations (e.g., Stevens \& Adams, 2013), and gender inequality in relation to board dynamics and managerial behavior and practice within sport organizations (e.g., Adriaanse, 2016). In regards to the latter, Adriaanse (2016) examined gender diversity on sport governing boards in 45 countries.

Corruption. The second social theme that emerged from the data set were related to corruption issues within sport $(n=13)$. Within the corruption theme, 11 of 13 studies were classified as systematic governance. In this sense, sport scholars have examined corruption within sport as a symptom of widespread system failures in governance. Appropriate governance mechanisms can therefore be used as a tool for the curbing, preventing or overcoming corruption issues within 


\section{GOVERNANCE IN SPORT: A SCOPING REVIEW}

sport. Our scoping review revealed that sport scholars have primarily focused on two issues: doping and match fixing. In relation to doping, scholars have examined the role of international and national anti-doping agencies in fighting against doping (e.g., Houlihan \& Preece, 2007; Miah, 2002). Other studies within this area explored, for example, the effectiveness and compliance of anti-doping codes and the adoption and implementation of anti-doping policies within sport organizations (Houlihan, 2014). In relation to match-fixing, researchers have explored mechanisms that could be used to prevent match fixing (e.g., Veuthey, 2014), the role of key stakeholders that result in governance failings and match-fixing scandals (e.g., Lee, 2015), and the potential use of international regulation and treaties to prevent match-fixing occurring (e.g., Serby, 2015).

\section{Future Directions and Emergent Areas of Research}

There are several observations that can be drawn from the findings of our scoping review generally and the mapping of the sport governance literature (Figure 3) in particular. First and foremost, it is apparent from our review that all three forms of governance (organizational, systemic, and political) have contributed to our understanding of governance issues within the context of sport. It is for this reason that we would argue that scholars should adopt a broader definition of sport governance (such as Henry and Lee's) in order to fully acknowledge the breadth, value, and utility of the concept. Based on the findings of our scoping review, we therefore concur with the remarks of Cornforth (2012) that an overtly narrow focus on (sport) governance as boards does not adequately reflect the changing nature in which (sport) organizations operate and therefore neglects the complexity of governance structures surrounding sport organizations. The benefit of adopting a broader definition of sport governance, we suggest, would be the opening 


\section{GOVERNANCE IN SPORT: A SCOPING REVIEW}

...up [of] new questions for research concerning the relationships between different parts of the governance system, such as how regulation, audit, inspection, and funding regimes can influence governance structures and practices at the organizational level, or what contribution other internal actors such as managers, staff, and members make to carrying out governance functions? (Cornforth, 2012, p. 1122)

Conceptualizing sport governance in this broader sense may therefore lead to the recognition of the role of other actors beyond the typical board-management relations that may also contribute to governance functions (Cornforth, 2012).

Second, and linked to the above discussion, our scoping study revealed that the three types of governance have emerged (i.e. studies published) around the same time period, suggesting that the conversations regarding the different types of sport governance have emerged simultaneously but independently (see supplementary Table 4). Future studies could undertake, for example, a citation path analysis that would be able to confirm this finding and further explore the connections between these different types of governance in more detail. This type of study would also provide a better understanding how the concept of governance has been imported into the sport management domain.

Furthermore, given the plurality of theoretical traditions and research contexts evident within the sport governance field, it may be fruitful to consider new or imported theoretical concepts (e.g., collaborative governance) and empirical sites (e.g., sport events and community sport) that have the potential to span general governance types. In moving beyond Henry and Lee's conceptualization of governance, can researchers start to examine the interrelationship between these governance approaches? For example, how can political governance issues be informed by systemic governance? What is the relationship between organizational and systemic 


\section{GOVERNANCE IN SPORT: A SCOPING REVIEW}

governance? Does poor organizational governance result in failures in systemic governance?

These issues have yet to be fully explored within the sport management literature and have the potential to contribute to the broader public administration and management literature.

Third, our scoping review found a large amount (approx. 40\%) of non-empirical studies within the sport governance literature. This can be partly explained by the aforementioned issues surrounding the definitional ambiguities surrounding sport governance, which has made the concept difficult to operationalize empirically. The amount of non-empirical studies could also be explained by methodological issues surrounding data access which, although commonplace in many other areas of research, would be particularly pronounced given the amount of emphasis and focus placed on the dominant international governing agencies such as FIFA and the IOC. Moreover, given the recent high profile cases of governance failures, it is hardly unsurprising that these agencies are not willing to discuss (at least publically) their inner governance practices.

Perhaps another explanation for a large number of non-empirical studies is to do with the way in which scholars have adopted the concept of governance as an analytical tool or device rather than as a theoretical framework. Our scoping review revealed that many scholars, particularly within the systemic and political governance domains, have adopted the term as an "empty signifier" (Offe, 2009, p. 550) in that they have used governance as a general term of reference to frame their study rather than as a theoretical framework per se. Offe (2009) provides a useful distinction here between governance as a way of explaining all modes of governing (Oberbegiff) and governance as a mode of governing (Genenbegriff). Many of the studies identified within our scoping review were the former not the latter. The result of which has been considerable amount of general governance-related debate and discussion within the literature 


\section{GOVERNANCE IN SPORT: A SCOPING REVIEW}

(hence the usage of terms such as 'the governance debate' (Grix, 2010)) but little in the way of theoretical development or empirical testing. There have been some promising exceptions, particularly within the organizational governance domain, that have begun to theorize the governance process (e.g., Ferkins \& Shilbury, 2015; O’Boyle, 2012), but similar attempts have not been made in other sport governance domains and these are exceptions rather than rules of thumb. The general outcome of which, we suggest, has been much 'talk' about sport governance but very little in the way of understanding what sport governance is, much less what it looks like in practice (Colebatch, 2014). Sport governance, then, much like the concept of governance more broadly, remains conceptually under-developed and lacks empirical support (Colebatch, 2014). As such, there is a clear need for more empirically driven research, underpinned by sport governance as a theoretical construct rather than analytical lens to provide evidence to support (or refute) the on going discussions and claims within the field.

Fourth, and what can be drawn from Figure 3 in particular, is that organizational governance has been used to examine a narrow range of research contexts (e.g., national sport organizations and professional sport), whereas systemic governance has been employed to examine a much wider range of research contexts. This finding could be interpreted to suggest that there is an explicit need to examine a number of additional specific areas, particularly within the organizational governance domain. It should be noted, however, that an absence of research spanning particular governance types, research contexts and social issues does not necessarily indicate a need for further study. Nonetheless, there are a number of contexts such as collegiate sport, community/grassroots sport, and sporting events that could provide fertile grounds for future research. We, however, suggest that this finding reveals a much more fundamental question about the nature of governance within the sporting domain and how we might study it. 


\section{GOVERNANCE IN SPORT: A SCOPING REVIEW}

It seems apparent from our review, that organizational governance has been (and continues to be) a useful perspective in which to examine what could be variously described as traditional sport organizations. The reality is, however, that not all sport organizations have boards nor do they adopt traditional organizational structures and designs. How, then, is it possible to study the governance arrangements of sport organizations without boards? How might governance be used to examine non-traditional organizational forms such as temporary, networked, or virtual sport organizations whereby the boundaries between the organization and the broader environment are becoming increasingly blurred (Misener \& Misener, 2017)? It is to these theoretically rather than empirically driven questions that intersect organizational, systemic and political forms of governance that we see particular value and merit in moving our knowledge and understanding of sport governance forward.

\section{Conclusion and Limitations}

The adoption of a scoping review method is a useful approach to examine the current state of sport governance research, especially given the emergent yet disparate nature of the domain. This study has sought to identify how sport governance has been utilized within the literature, map out the sport governance literature, and identify potential future directions of research. To this end, this study has provided the following contributions to the sport management literature. First, we offer the first attempt to organize and synthesize the sport governance literature. Scoping reviews are particularly beneficial in assessing the range and extent of research in an area using a systematic approach. The limitation of a scoping review (unlike a systematic review or meta-synthesis) is that they do not attempt to be fully exhaustive nor do they make any assessment of research quality. It is for this reason that we do not claim to have identified every sport governance study nor did we make any judgement on the quality of the research conducted. 


\section{GOVERNANCE IN SPORT: A SCOPING REVIEW}

Consequently, we would suggest from our review that there is a further need to carry out systematic reviews in order to understand the full extent and quality of research that has been conducted into specific areas of sport governance; perhaps systematic reviews in each of the three domains (political, systemic, organizational) would be a good starting point. Furthermore, another limitation of our scoping study is that despite identifying a number of topic areas (sport policy, law, CSR), we did not systematically identify nor assess the range and extent of theoretical approaches used by those interested in sport governance. Further systematic approaches to reviewing literature would facilitate a better understanding of the different theoretical traditions that characterize the sport governance domain.

As a second contribution, this review provides the first attempt to illustrate (or map) the sport governance domain (Figure 3). As with our attempt to organize and structure the literature, we do not claim this conceptualization is fully exhaustive and journal constraints have inhibited a detailed discussion of all the domains identified. Our attempt to map the literature does, however, illustrate the current breadth of the sport governance literature and provide a useful framework in which to identify future areas of research - some of which we have identified herein. In doing so, the process has also provided a more specific third contribution by extending Henry and Lee's (2004) definition of sport governance by further delineated sub-categories and types of studies that have been conducted within the three forms of governance identified by the authors (see Table 3).

In reflecting upon the process more generally, scoping reviews have increasingly become a popular approach to synthesizing knowledge. Despite scoping and systematic reviews being commonplace in other fields, there have been very few scoping reviews conducted within the sport management domain (for exception Inoue et al., 2015). As the field begins to mature and 
GOVERNANCE IN SPORT: A SCOPING REVIEW

its knowledge base continues to expand, there will be an increasing need to organize and synthesize knowledge in other topic areas relevant to the sport management domain. As such we would encourage sport scholars more generally to produce more systematic approaches to reviewing literature. We suggest, as others have done elsewhere (Coloquhoun et al. 2014), that scoping and systematic reviews have potential to advance understanding in research areas, avoid or at least reduce confusion, facilitate further collaboration, and help to consolidate evidence to inform policy and practice more effectively. 
GOVERNANCE IN SPORT: A SCOPING REVIEW

\section{References}

Adriaanse, J. (2016). Gender diversity in the governance of sport associations: The Sydney scoreboard global index of participation. Journal of Business Ethics, 137, 149-160. doi:10.1007/s10551-015-2550-3

Adriaanse, J. A., \& Claringbould, I. (2014). Gender equality in sport leadership: From the Brighton declaration to the Sydney scoreboard. International Review for the Sociology of Sport, 51, 547-566. doi:10.1177/1012690214548493

Adriaanse, J., \& Schofield, T. (2014). The impact of gender quotas on gender equality in sport governance. Journal of Sport Management, 28, 498-513. doi:10.1123/jsm.2013-0108

Arksey, H., \& O’Malley, L. (2005). Scoping studies: towards a methodological framework. International Journal of Social Research Methodology, 8, 19-32. doi:10.1080/1364557032000119616

Babiak, K. (2007). Determinants of interorganizational relationships: The case of a Canadian nonprofit sport organization. Journal of Sport Management, 21, 338-376. doi:10.1123/jsm.21.3.338

Babiak, K., \& Thibault, L. (2009). Challenges in multiple cross-sector partnerships. Nonprofit and Voluntary Sector Quarterly, 38, 117-143. doi:10.1177/0899764008316054

Bellamy, R., \& Palumbo, A. (2010). From government to governance. London: Routledge. Bevir, M. (2012). Governance: A very short introduction. Oxford: Oxford University Press.

Bevir, M., \& Rhodes, R. A. W. (2008). The differentiated polity as narrative. British Journal of Politics and International Relations, 10, 729-734. doi:10.1111/j.1467-856X.2008.00325.x 


\section{GOVERNANCE IN SPORT: A SCOPING REVIEW}

Boudreaux, C. J., Karahan, G., Coats, M., John, C., Gokhan, B., Morris, K., \& Sanchez, A. R. (2016). Managerial finance bend it like FIFA: Corruption on and off the pitch. Managerial Finance, 42, 866-878. doi:10.1108/MF-01-2016-0012

Brand, A., Niemann, A., \& Spitaler, G. (2013). The two-track Europeanisation of football : EUlevel pressures, transnational dynamics and their repercussions within different national contexts. International Journal of Sport Policy and Politics, 5, 95-112.

Braun, V., \& Clarke, V. (2006). Using thematic analysis in psychology. Qualitative Research in Psychology, 3, 77-101. doi:10.1191/1478088706

Byers, T., Anagnostopoulos, C., \& Brooke-Holmes, G. (2015). Understanding control in nonprofit organisations: moving governance research forward? Corporate Governance The International Journal of Business in Society, 15, 134-145. doi:10.1108/CG-06-20140072

Chappelet, J.-L. (2011). Towards better Olympic accountability. Sport in Society, 14, 319-331. doi:10.1080/17430437.2011.557268

Chappelet, J.-L. (2016). From Olympic administration to Olympic governance. Sport in Society, 19, 739-751. doi:10.1080/17430437.2015.1108648

Colebatch, H. (2014). Making sense of governance. Policy and Society, 33, 3017-316. doi:10.1016/j.polsoc.2014.10.001

Colquhoun, H. L., Levac, D., O’Brien, K. K., Straus, S., Tricco, A. C., Perrier, L., \& Moher, D. (2014). Scoping reviews: time for clarity in definition, methods, and reporting. Journal of Clinical Epidemiology, 67, 1291-1294. doi:10.1016/j.jclinepi.2014.03.013 


\section{GOVERNANCE IN SPORT: A SCOPING REVIEW}

Cornforth, C. (2012). Nonprofit governance research: Limitations of the focus on boards and suggestions for new directions. Nonprofit and Voluntary Sector Quarterly, 41, 1116-1135. doi:10.1177/0899764011427959

Cousens, L., \& Slack, T. (2005). Field-level change: The case of North American major league professional sport. Journal of Sport Management, 19, 13-42. doi:10.1123/jsm.19.1.13

Craven, R. (2014). Football and state aid: Too important to fail? The International Sports Law Journal, 14, 205-217. doi:10.1007/s40318-014-0049-1

Dimitropoulos, P., Leventis, S., \& Dedoulis, E. (2016). Managing the European football industry: UEFA's regulatory intervention and the impact on accounting quality. European Sport Management Quarterly, 16, 459-486. doi:10.1080/16184742.2016.1164213

Dolles, P. H., \& Soderman, P. S. (2011). Managing sport: governance and performance. Best papers from the "Sport as Business" track at the EURAM annual meeting in Rome 2010. Sport, Business and Management: An International Journal, 1, doi:10.1108/sbm.2011.51201caa.002

Dorsey, J. M. (2015). Asian football: A cesspool of government interference, struggles for power, corruption, and greed. International Journal of the History of Sport, 32, 1001-1015. doi:10.1080/09523367.2015.1040222

Dortants, M., \& Knoppers, A. (2016). The organization of diversity in a boxing club: Governmentality and entangled rationalities. Culture and Organization, 22, 245-261. doi:10.1080/14759551.2016.1157804

Erturan, E., Brison, N., \& Allen, T. (2012). Comparative analysis of university sports in the U.S. and Turkey. Choregia, 8, 5-24. doi:10.4127/ch.2012.0061 


\section{GOVERNANCE IN SPORT: A SCOPING REVIEW}

Ferkins, L., \& Shilbury, D. (2012). Good boards are strategic: What does that mean for sport governance? Journal of Sport Management, 26, 67-89. doi:10.1123/jsm.26.1.67

Ferkins, L., \& Shilbury, D. (2015). Board strategic balance: An emerging sport governance theory. Sport Management Review, 18, 489-500. doi:10.1016/j.smr.2014.12.002

Ferkins, L., Shilbury, D., \& McDonald, G. (2005). The role of the board in building strategic capability: Towards an integrated model of sport governance research. Sport Management Review, 8, 195-225. doi:10.1016/S1441-3523(05)70039-5

Franck, E. (2010). Private firm, public corporation or member's association governance structures in European football. International Journal of Sport Finance, 5(2), 108-127. doi:10.5167/uzh-35150

García, B., \& Weatherill, S. (2012). Engaging with the EU in order to minimize its impact: sport and the negotiation of the Treaty of Lisbon. Journal of European Public Policy, 19, 238256. doi:10.1080/13501763.2011.609710

Gardiner, S., \& Welch, R. (2011). Nationality and protectionism in football: why are FIFA’s “6+ 5 rule” and UEFA’s “home-grown player rule” on the agenda? Soccer \& Society, 12, 774787. doi:10.1080/14660970.2011.609679

Geeraert, A., \& Drieskens, E. (2015). The EU controls FIFA and UEFA: A principal-agent perspective. Journal of European Policy, 22, 1448-1446.

doi:10.1080/13501763.2015.1022206

Girginov, V. (2012). Governance of the London 2012 Olympic Games legacy. International Review for the Sociology of Sport, 47, 543-558. doi:10.1177/1012690211413966

Goodwin, M., \& Grix, J. (2011). Bringing structures back in: The “governance narrative”, the “decentred approach” and "asymmetrical network governance” in the education and sport 


\section{GOVERNANCE IN SPORT: A SCOPING REVIEW}

policy communities. Public Administration, 89, 537-556. doi:10.1111/j.14679299.2011.01921.x

Green, M., \& Houlihan, B. (2006). Governmentality, modernization and the “disciplining” of national sporting organizations: Athletics in Australia and the United Kingdom. Sociology of Sport Journal, 23, 47-71. doi:10.1123/ssj.23.1.47

Grix, J. (2009). The impact of UK sport policy on the governance of athletics. International Journal of Sport Policy and Politics, 1, 31-49. doi:10.1080/19406940802681202

Grix, J., \& Phillpots, L. (2011). Revisiting the "governance narrative”: “asymmetrical network governance” and the deviant case of the sports policy sector. Public Policy and Administration, 26, 3-19. doi:10.1177/0952076710365423

Henry, I., \& Lee, P. C. (2004). Governance and ethics in sport. In S. Chadwick \& J. Beech (Eds.), The Business of Sport Management. (pp. 25-41). Harlow: Pearson Education.

Houlihan, B. (2014). Achieving compliance in international anti-doping policy: An analysis of the 2009 World Anti-Doping Code. Sport Management Review, 17, 265-276. doi:10.1016/j.smr.2013.10.002

Houlihan, B., \& Preece, A. (2007). Independence and accountability: The case of the drug free sport directorate, the UK’s National Anti-Doping Organisation. Public Policy and Administration, 22, 381-402. doi:10.1177/0952076707081584

Hoye, R. (2006). Governance reform in Australian horse racing. Managing Leisure, 11, 129138. doi:10.1080/13606710500520338

Hoye, R., \& Cuskelly, G. (2003). Board-executive relationships within voluntary sport organisations. Sport Management Review, 6, 53-73. doi:10.1016/S1441-3523(03)70053-9 Hoye, R., \& Cuskelly, G. (2007). Sport governance. London: Routledge. 


\section{GOVERNANCE IN SPORT: A SCOPING REVIEW}

Inoue, Y., Berg, B. K., \& Chelladurai, P. (2015). Spectator sport and population health: A scoping study. Journal of Sport Management, 29, 705-725. doi:10.1123/JSM.2014-0283

Kikulis, L. M. (2000). Continuity and change in governance and decision making in national sport organizations: institutional explanations. Journal of Sport Management, 14, 293-320. doi:10.1123/jsm.14.4.293

King, N. A. (2017). Sport governance : an introduction. London: Routledge.

Kjær, A. M. (2004). Governance. Cambridge: Polity Press.

Kornbeck, J. (2016). Anti-doping governance and transparency: a European perspective. International Sports Law Journal, 16, 118-122. doi:10.1007/s40318-016-0098-8

Leopkey, B., \& Parent, M. M. (2012). The (Neo) institutionalization of legacy and its sustainable governance within the Olympic Movement. European Sport Management Quarterly, 12, 437-455. doi:10.1080/16184742.2012.693116

Leopkey, B., \& Parent, M. M. (2015). Stakeholder perspectives regarding the governance of legacy at the Olympic Games. Annals of Leisure Research, 18, 528-548. doi:10.1080/11745398.2015.1092388

Levac, D., Colquhoun, H., \& O’Brien, K. K. (2010). Scoping studies: advancing the methodology. Implementation Science, 5 (69). doi:10.1186/1748-5908-5-69

Lusted, J., \& O’Gorman, J. (2010). The impact of New Labour's modernisation agenda on the English grass-roots football workforce. Managing Leisure, 15, 140-154. doi:10.1080/13606710903448236

MacDonald, R., \& Ramsey, I. (2016). The Australian Sports Commission's “Governance Reform in Sport" discussion paper and voting rules in corporate constitutions. Company and Securities Law Journal, 34, 387-402. 


\section{GOVERNANCE IN SPORT: A SCOPING REVIEW}

Marsh, D. (2008). What is at stake? A response to Bevir and Rhodes. British Journal of Politics and International Relations, 10, 735-739. doi:10.1111/j.1467-856X.2008.00341.x

Meier, H. E., \& Garcia, B. (2015). Protecting private transnational authority against public intervention: FIFA’s power over national governments. Public Administration, 93, 890906. doi:10.1111/padm.12208

Miah, A. (2002). Governance, harmonisation, \& genetics: The world anti-doping agency \& its European connections. European Sport Management Quarterly, 2, 350-369. doi:10.1080/16184740208721933

Miller, S. (2011). Good governance and anti-doping policy: an international federation view. International Journal of Sport Policy and Politics, 3, 279-288. doi:10.1080/19406940.2011.577082

Nichols, G., Grix, J., Ferguson, G., \& Griffiths, M. (2016). How sport governance impacted on Olympic legacy: A study of unintended consequences and the "Sport Makers" volunteering programme. Managing Sport and Leisure, 21, 61-74. doi:10.1080/23750472.2016.1181984

Misener, K., \& Misener, L. (2017). Grey is the new black: Advancing understanding of new organizational forms and blurring sector boundaries in sport management. Journal of Sport Management, 31, 125-132. doi:10.1123/jsm.2017-0030

Nite, C. (2017). Message framing as institutional maintenance: The National Collegiate Athletic Association's institutional work of addressing legitimate threats. Sport Management Review, 20, 338-351. doi:10.1016/j.smr.2016.10.005

O’Boyle, I. (2012). Corporate governance applicability and theories within not-for-profit sport management. Corporate Ownership and Control, 9, 335-342. doi:10.22495/cocv9i2c3art3 


\section{GOVERNANCE IN SPORT: A SCOPING REVIEW}

O’Brien, D., \& Slack, T. (2003). An analysis of change in an organizational field: The professionalization of English rugby union. Journal of Sport Management, 17, 417-448. doi:10.1123/jsm.17.4.417

Offe, C. (2009). Governance: An “empty signifier”. Constellations, 16(4), 550-562. doi:10.1111/j.1467-8675.2009.00570.x

Osborne, D., \& Gaebler, T. (1992). Reinventing government: How the entrepreneurial spirit is transforming the public sector. New York: Plume.

Parent, M. (2016). The governance of the Olympic Games in Canada. Sport in Society, 19, 796816. doi:10.1080/17430437.2015.1108652

Parent, M., Rouillard, C., \& Leopkey, B. (2011). Issues and strategies pertaining to the Canadian governments’ coordination efforts in relation to the 2010 Olympic Games. European Sport Management Quarterly, 11, 337-369.

Pham, M. T., Rajić, A., Greig, J. D., Sargeant, J. M., Papadopoulos, A., \& McEwen, S. A. (2014). A scoping review of scoping reviews: advancing the approach and enhancing the consistency. Research Synthesis Methods, 5, 371-385. doi:10.1002/jrsm.1123

Phillips, P., \& Newland, B. (2014). Emergent models of sport development and delivery: The case of triathlon in Australia and the US. Sport Management Review, 17, 107-120. doi:10.1016/j.smr.2013.07.001

Pierre, J. (2000). Debating governance. Oxford University Press.

Radzi, W. M., \& Abdullah, R. (2010). Through rose-tinted glasses: Muslim women sport managers in Malaysia. Asian Women, 26(3), 1-28. doi:10.14431/aw.2010.09.26.3.1

Rhodes, R. A. W. (1996). The new governance: Governing without government. Political Studies, 44, 652-667. doi:10.1111/j.1467-9248.1996.tb01747.x 


\section{GOVERNANCE IN SPORT: A SCOPING REVIEW}

Sam, M. P. (2012). Targeted investments in elite sport funding: Wiser, more innovative and strategic? Managing Leisure, 17, 207-220. doi:10.1080/13606719.2012.674395

Serby, T. (2015). The Council of Europe Convention on Manipulation of Sports Competitions: the best bet for the global fight against match-fixing? The International Sports Law Journal, 15, 83-100. doi:10.1007/s40318-015-0069-5

Serby, T. (2016). The state of EU sports law : lessons from UEFA's “ Financial Fair Play” regulations. The International Sports Law Journal, 16, 37-51. doi:10.1007/s40318-0160091-2

Sherry, E., \& Shilbury, D. (2011). Impact of social expectations on ethical governance of sport organisations. Annals of Leisure Research, 10, 413-430. doi:10.1080/11745398.2007.9686774

Shilbury, D. (2015). Keynote address: Global sport governance challenges: A research opportunity. Paper presented at the 24th Annual European Association for Sport Management Conference, September, Warsaw, Poland.

Shilbury, D., O’Boyle, I., \& Ferkins, L. (2016). Towards a research agenda in collaborative sport governance. Sport Management Review, 19, 479-491. doi:10.1016/j.smr.2016.04.004

Sibson, R. (2010). “I was banging my head against a brick wall”: Exclusionary power and the gendering of sport organizations. Journal of Sport Management, 24, 379-399. doi:10.1123/jsm.24.4.379

Sotiriadou, K. (2009). The Australian sport system and its stakeholders: development of cooperative relationships. Sport in Society, 12, 842-860. doi:10.1080/17430430903053067 


\section{GOVERNANCE IN SPORT: A SCOPING REVIEW}

Stevens, J., \& Adams, C. (2012). “Together we can make it better”: Collective action and governance in a girls’ ice hockey association. International Review for the Sociology of Sport, 48, 658-672. doi:10.1177/1012690212454466

Van Den Hurk, M., \& Verhoest, K. (2016). The challenge of using standard contracts in publicprivate partnerships. Public Management Review, 18, 278-299.

doi:10.1080/14719037.2014.984623

van Kleef, R. (2014). The legal status of disciplinary regulations in sport. The International Sports Law Journal, 14, 24-45. doi:10.1007/s40318-013-0035-z

Wagner, U. (2011). Towards the construction of the World Anti-Doping Agency: Analyzing the approaches of FIFA and the IAAF to doping in sport. European Sport Management Quarterly, 11, 445-470. doi:10.1080/16184742.2011.624107

Washington, M., \& Ventresca, M. J. (2008). Institutional contradictions and struggles in the formation of U.S. collegiate basketball, 1880-1938. Journal of Sport Management, 22, 2049. doi:10.1123/jsm.22.1.30

Weinberg, B. (2012). “The future is Asia”? The role of the Asian Football Confederation in the governance and development of football in Asia. The International Journal of the History of Sport, 29, 535-552. doi:10.1080/09523367.2012.658216

Welford, J., García, B., \& Smith, B. (2015). A “healthy” future? Supporters’ perceptions of the current state of English football. Soccer \& Society, 16, 322-343.

doi:10.1080/14660970.2014.961380

Yiamouyiannis, A., \& Osborne, B. (2012). Addressing gender inequities in collegiate sport: Examining female leadership representation within NCAA sport governance. Sage Open, 2(2), 1-13. doi:10.1177/2158244012449340 
GOVERNANCE IN SPORT: A SCOPING REVIEW

Zeidan, O. S., \& Fauser, S. G. (2015). Corporate governance and corporate social responsibility The case of FIFA. Problems and Perspectives in Management, 13, 183-192.

** a full list of database citations is available from the corresponding author 